\title{
Projected changes to winter temperature characteristics over Canada based on an RCM ensemble
}

\author{
Dae II Jeong ${ }^{1}$ Laxmi Sushama $^{1} \cdot$ Gulilat Tefera Diro $^{1} \cdot$ M. Naveed Khaliq ${ }^{1,2}$
}

Received: 25 June 2015 / Accepted: 30 October 2015 / Published online: 19 November 2015

(C) The Author(s) 2015. This article is published with open access at Springerlink.com

\begin{abstract}
Cold temperature and associated extremes often impact adversely human health and environment and bring disruptions in economic activities during winter over Canada. This study investigates projected changes in winter (December to March) period cold extreme days (i.e., cold nights, cold days, frost days, and ice days) and cold spells over Canada based on 11 regional climate model (RCM) simulations for the future 2040-2069 period with respect to the current 1970-1999 period. These simulations, available from the North American Regional Climate Change Assessment Program, were obtained with six different RCMs, when driven by four different Atmosphere-Ocean General Circulation Models, under the Special Report on Emissions Scenarios A2 scenario. Based on the reanalysis boundary conditions, the RCM simulations reproduce spatial patterns of observed mean values of the daily minimum and maximum temperatures and inter-annual variability of the number of cold nights over different Canadian climatic regions considered in the study. A comparison of current and future period simulations suggests decreases in the frequency of cold extreme events (i.e., cold nights, cold days and cold spells) and in selected return levels of maximum duration of cold spells over the entire study domain. Important regional differences are noticed as the simulations generally indicate smaller decreases in the characteristics of extreme cold events over western Canada compared to the other regions. The analysis also suggests an increase in the
\end{abstract}

Dae Il Jeong

jeong@sca.uqam.ca

1 Centre ESCER (Étude et Simulation du Climat à l'Échelle Régionale), Université du Québec à Montréal, 201 Ave. President-Kennedy, Montreal, QC H2X 3Y7, Canada

2 National Research Council, Ottawa, ON, Canada frequency of midwinter freeze-thaw events, due mainly to a decrease in the number of frost days and ice days for all Canadian regions. Especially, densely populated southern and coastal Canadian regions will require in depth studies to facilitate appropriate adaptation strategies as these regions are clearly expected to experience large increases in the frequency of freeze-thaw events.

Keywords Climate change - Cold temperature extremes . Regional climate model $\cdot$ Canada

\section{Introduction}

According to the Intergovernmental Panel on Climate Change (IPCC 2012), significant changes in the frequency, spatial extent, and duration of temperature extremes can be expected in future climate. Since these extremes have major effects on various human and natural systems, it is relevant to assess projected changes to temperature extremes in a future warmer climate. Based on observations gathered since 1950, an overall decrease in the number of cold days, and an overall increase in the number of hot days have been reported at the global scale (IPCC 2012, 2013). Furthermore, a decrease in the frequency of cold days and an increase in the frequency of hot days have been suggested for the twenty-first century, based on projections of global climate models contributing to the Coupled Model Intercomparison Project Phases 3 and 5 (CMIP3 and CMIP5) (IPCC 2012, 2013; Ma et al. 2012; Peings et al. 2013; Sillmann et al. 2013). Several studies (e.g., Beniston et al. 2007; Islam et al. 2009; Kunkel et al. 2010; Fischer and Schär 2010; Ramos et al. 2011) have investigated climate change impacts on temperature extremes at the regional scale by using outputs of regional climate models 
(RCMs), particularly for the major heat waves over Europe during the last two decades (Vautard et al. 2013). Cold temperature extremes, however, have received less attention compared to hot temperature extremes at the regional scale (e.g., Islam et al. 2009).

Over Canada, cold temperature and associated extremes such as cold spells during winter impact human health and lead to environmental hazards and severe disruptions in economic activities (Shabbar and Bonsal 2003). Certainly, changes in cold temperature events will result in both positive and negative impacts on certain sectors. For instance, a future decrease in the frequency of cold extremes could alleviate cold-related injuries and deaths, and reduce energy consumption. However, it can have significant negative impacts on water resources and infrastructure management, forestry, northern transportation, and nonrenewable resource exploitation in Canada (Lemmen et al. 2008).

Changes in cold temperature extremes are already evident in Canada. Shabbar and Bonsal (2003) reported decreases (increases) in the observed frequency and duration of cold spells in western (eastern) Canada for the 1950-1998 period, while decreasing trends in observed cold days, cold nights, and frost days have been reported over Canada for the 1950-2003 period by Vincent and Mekis (2006). Based on the global scale CMIP3 and CMIP5 projections, several studies (Lemmen et al. 2008; IPCC 2012, 2013; Jeong et al. 2012, 2013; Sillmann et al. 2013) have suggested that cold days will become less frequent with future warming climate conditions over Canada. However, detailed regional scale projections of cold temperature extremes based on high-resolution RCMs are not yet available for Canada.

The main purpose of this study is to evaluate changes to cold temperature extremes (i.e., cold nights, cold days, frost days, ice days, and cold spells) for the future 2040 2069 period with respect to the current 1970-1999 period over Canada, for the winter (December to March; DJFM) period, based on a multi-RCM ensemble available from the North American Regional Climate Change Assessment Program (NARCCAP) (Mearns et al. 2012). The aim of the NARCCAP is to produce high-resolution climate change information for regional impact studies and the necessary ensembles required to estimate various types of uncertainties associated with climate change projections over North America.

This paper is organized as follows. Section 2 briefly describes the NARCCAP RCMs and their driving fields, the observed gridded dataset, and the study area. Detailed methodology to analyze climate change impacts on cold temperature extremes is described in Sect. 3. The results of the study are presented in Sect. 4 and a discussion and conclusions are provided in Sect. 5 .

\section{Models, data, and study area}

Simulations from six different NARCCAP RCMs driven by National Center for Environmental Prediction Reanalysis II (NCEP2) (Kistler et al. 2001) and four Atmosphere-Ocean General Circulation Models (AOGCMs) are considered. The simulation domain covers the USA and most of Canada, except for the high latitude Arctic area, at the spatial resolution of $50 \mathrm{~km}$ (Mearns et al. 2012). Though the NARCCAP domain covers most of North America, the analysis presented here is focused on Canada only. The NCEP2 driven simulations spanning the 1981-2003 period (referred to hereafter as validation period) are used to assess ability of RCMs in reproducing observed characteristics of cold temperature events, while those driven by AOGCMs are used to evaluate projected changes to the characteristics of cold temperature events for the future 2040-2069 period with respect to the current 19701999 period. All simulations considered in this study are summarized in Table 1. Hereafter, the AOGCM-driven simulations will be collectively referred to as RCM-AOGCMs and those driven by NCEP2 will be referred to as RCM-NCEP2s.

The six RCMs considered are the CRCM (Canadian RCM; Caya and Laprise 1999), ECP2 (updated Experimental Climate Prediction Center's version of the Regional Spectral Model; Juang et al. 1997), HRM3 (third-generation Hadley Center RCM; Jones et al. 2003), MM5I (fifthgeneration Pennsylvania State University-National Center for Atmospheric Research Mesoscale Model run by the Iowa State University modeling group; Grell et al. 1993), RCM3 (Abdus Salam International Center for Theoretical Physics RCM version 3; Pal et al. 2007), and WRFG (Weather Research Forecasting model with the Grell scheme; Grell and Devenyi 2002). These RCMs were selected by the NARCCAP to provide a variety of model physics and/or to use models that have already performed multiyear climate change experiments (Mearns et al. 2012). These models have significantly different physics, especially for the parameterized sub-grid scale processes such as turbulence, radiative transport, boundary layer effects, and moist processes (Wehner 2013).

Table 1 The 6 RCM-NCEP2 and 11 RCM-AOGCM combinations considered in the study

\begin{tabular}{llllll}
\hline RCM & NCEP & \multicolumn{4}{l}{ Driving AOGCM models } \\
\cline { 3 - 6 } & & CCSM & CGCM3 & GFDL & HadCM3 \\
\hline CRCM & $\mathrm{X}$ & $\mathrm{X}$ & $\mathrm{X}$ & & \\
ECP2 & $\mathrm{X}$ & & & $\mathrm{X}$ & \\
HRM3 & $\mathrm{X}$ & & & $\mathrm{X}$ & $\mathrm{X}$ \\
MM5I & $\mathrm{X}$ & $\mathrm{X}$ & & & $\mathrm{X}$ \\
RCM3 & $\mathrm{X}$ & & $\mathrm{X}$ & $\mathrm{X}$ & \\
WRFG & $\mathrm{X}$ & $\mathrm{X}$ & $\mathrm{X}$ & & \\
\hline
\end{tabular}


The four driving AOGCMs are CCSM3 (Community Climate System Model, version 3 of the National Center for Atmospheric Research (NCAR); Collins et al. 2006), CGCM3 (Coupled General Circulation Model version 3 of the Canadian Center for Climate Modelling and Analysis (CCCma); Flato 2005), GFDL (Geophysical Fluid Dynamics Laboratory climate model version 2.1; GFDM GAMDT 2004) and HadCM3 (Hadley Centre Coupled Model version 3; Gordon et al. 2000; Pope et al. 2000). It must be noted that the AOGCM simulations correspond to the SRES (Special Report on Emissions Scenarios) A2 scenario, which is at the higher end of the SRES emissions scenarios and hence is often preferred for impacts and adaptation related studies. Further details about the NARCCAP and participating RCMs and AOGCMs are available in Mearns et al. (2012) and also at the NARCCAP web site (www.narccap.ucar.edu).

The gridded observations of daily maximum and minimum temperatures ( $\mathrm{T}_{\min }$ and $\mathrm{T}_{\max }$ hereafter) over Canada, used in this study for validation purposes, are obtained from Hopkinson et al. (2011). This gridded dataset was developed from daily observations from Environment Canada climate stations using a thin plate smoothing spline surface fitting method and covers the Canadian landmass south of $60^{\circ} \mathrm{N}$ and is available at $10 \mathrm{~km}$ resolution.

The Canadian climatic regions (Fig. 1) defined by Plummer et al. (2006), based on climatic homogeneity, are used in this study to evaluate climate change impacts on cold temperature extremes at the regional scale. It must be noted that many studies over the region, including Mladjic et al. (2011), Mailhot et al. (2011) and Jeong et al. (2015), also employed the same climatic regions to

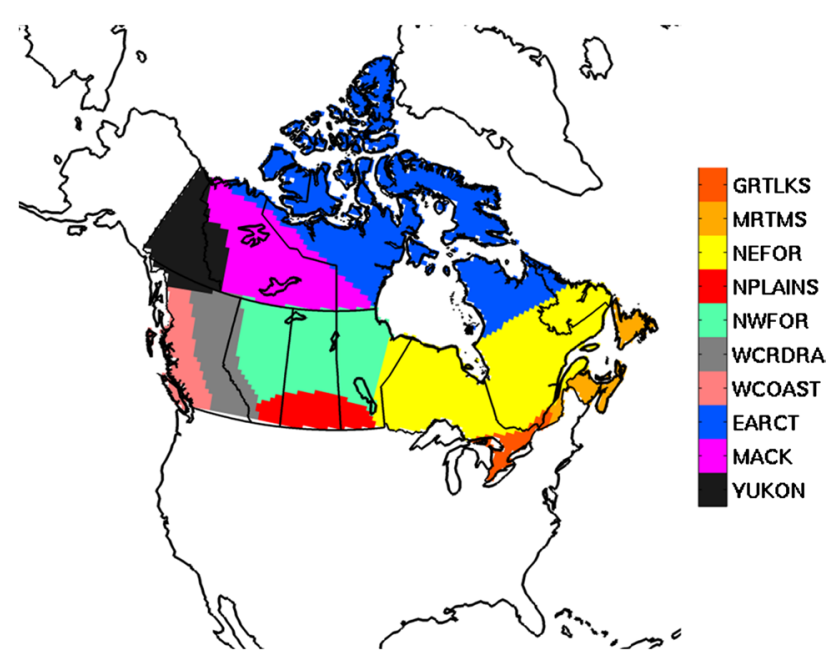

Fig. 1 Canadian climatic regions: (1) YUKON, (2) MACK, (3) EARCT, (4) WCOAST, (5) WCRDRA, (6) NWFOR, (7) NPLAINS, (8) NEFOR, (9) MRTMS, and (10) GRTLKS (from Mladjic et al. 2011) study changes in characteristics of extreme precipitation and temperature events. These 10 climatic regions are: Yukon Territory (YUKON), Mackenzie Valley (MACK), and East Arctic (EARCT) in the north; West Coast (WCOAST), Western Cordillera (WCRDRA), Northwest Forest (NWFOR), and Northern Plains (NPLNS), distributed along the western and prairie regions of Canada; and the Northeast Forest (NEFOR), Canadian Maritimes (MRTMS), and Great Lakes (GRTLKS) in the eastern part of Canada.

\section{Methodology}

\subsection{Definitions of indices}

A set of extreme indices has been recommended by the Expert Team on Climate Change Detection and Indices (ETCCDI) (Zhang et al. 2011). In this study, four cold extreme day indices, i.e., cold night, cold day, frost day, and ice day, recommended by the ETCCDI, are considered. The cold night and cold day are percentile basedthreshold indices. The cold nights are the days with $\mathrm{T}_{\min }$ less than the local threshold of $\mathrm{T}_{\min }$, and the cold days are the days with $T_{\max }$ less than the local threshold of $T_{\max }$. The local thresholds for cold night and cold day for the RCM-NCEP2s correspond to the 10th percentile of daily $\mathrm{T}_{\min }$ and $\mathrm{T}_{\max }$ time series at each grid point for the validation (1981-2003) winter (DJFM) period. Similarly, for the RCM-AOGCMs, the local thresholds for $\mathrm{T}_{\min }$ and $\mathrm{T}_{\max }$ correspond to the 10th percentile of $\mathrm{T}_{\min }$ and $\mathrm{T}_{\max }$ time series at each grid point for the current (1970-1999) winter period of the respective RCM-AOGCM simulation. The cold nights and cold days for the RCM-AOGCMs for the future 2040-2069 period are identified based on the thresholds calculated from the RCM-AOGCMs for the current period to analyze climate change impacts on cold extreme days.

Determination of local thresholds for $\mathrm{T}_{\min }$ and $\mathrm{T}_{\max }$ to identify cold nights and cold days could be problematic as all RCM simulations have biases. If an RCM underestimates daily $\mathrm{T}_{\min }$ and $\mathrm{T}_{\max }$ values, it obviously overestimates the number of cold nights and cold days based on the $\mathrm{T}_{\min }$ and $\mathrm{T}_{\max }$ thresholds calculated from observations. This bias could also propagate and affect projected changes to the number of cold nights, cold days, and also cold spells. We, therefore, identify cold nights and cold days for each model based on the local thresholds calculated from the simulated temperatures of the same model instead of those from observations (Fischer and Schär 2010; Vautard et al. 2013). To account for the seasonal cycle, smoothed 10th percentile thresholds were calculated for each calendar day using a 15-day moving average. 
The frost and ice days are identified based on absolute-threshold indices. The frost days are the days with $\mathrm{T}_{\text {min }}$ less than $0{ }^{\circ} \mathrm{C}$ and the ice days are the days with $\mathrm{T}_{\max }$ less than $0{ }^{\circ} \mathrm{C}$. These indices are important as their threshold is the melting point of ice. Changes in the frequency of midwinter freeze-thaw events could impact several natural hazards such as snow slides and avalanches, landslides, erosion of clayey slopes and friable sandstone cliffs, ice jam, and freezing rain. Freeze-thaw days are defined as the days with $\mathrm{T}_{\text {min }}$ below $0{ }^{\circ} \mathrm{C}$ and $\mathrm{T}_{\max }$ above $0{ }^{\circ} \mathrm{C}$.

A cold spell event can be defined as a period with $T_{\text {min }}$ below a temperature threshold of $\mathrm{T}_{\min }$ for a specific duration threshold. There are several definitions to identify cold spell events by employing different temperature and duration thresholds. For instance, ETCCDI and several other studies (Islam et al. 2009; Ramos et al. 2011; Peings et al. 2013; Sillmann et al. 2013; Wang et al. 2013) defined a cold spell as a period of at least six consecutive days (i.e., duration threshold) with daily $\mathrm{T}_{\min }$ below the 10th percentile of $\mathrm{T}_{\min }$ (i.e., temperature threshold) for a given reference period. Kyselý et al. (2012) and Shabbar and Bonsal (2003), however, used two and three consecutive days as the duration threshold and 5th and 20th percentiles of $\mathrm{T}_{\text {min }}$ as the temperature threshold, respectively, to identify a cold spell. In this study, a cold spell event is defined as a period with $\mathrm{T}_{\text {min }}$ below the 10th percentile of $\mathrm{T}_{\min }$ series (i.e., cold night) for at least a duration threshold. Duration thresholds of 1-10 days are considered here.

Based on the identified cold extreme days and cold spells, the average number of cold nights, cold days, cold spell events, frost days, ice days, freeze-thaw days as well as the maximum duration of cold spells per winter are calculated for the validation period NCEP 2 driven RCM simulations and for the current and future period AOGCM driven RCM simulations. (a) Mean $\operatorname{Tmin}\left({ }^{\circ} \mathrm{C}\right)$

Obs.

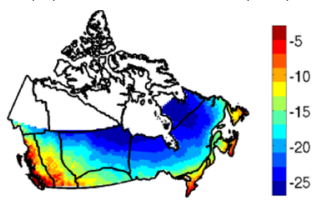

(b) Mean $\operatorname{Tmax}\left({ }^{\circ} \mathrm{C}\right)$

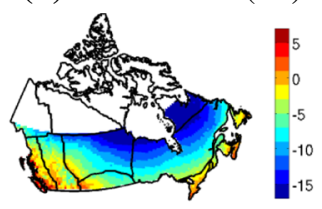

(c) DTR $\left({ }^{\circ} \mathrm{C}\right)$

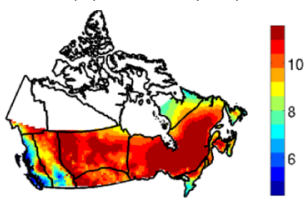

Selected statistics derived from differences between RCM-NCEP2 simulations and
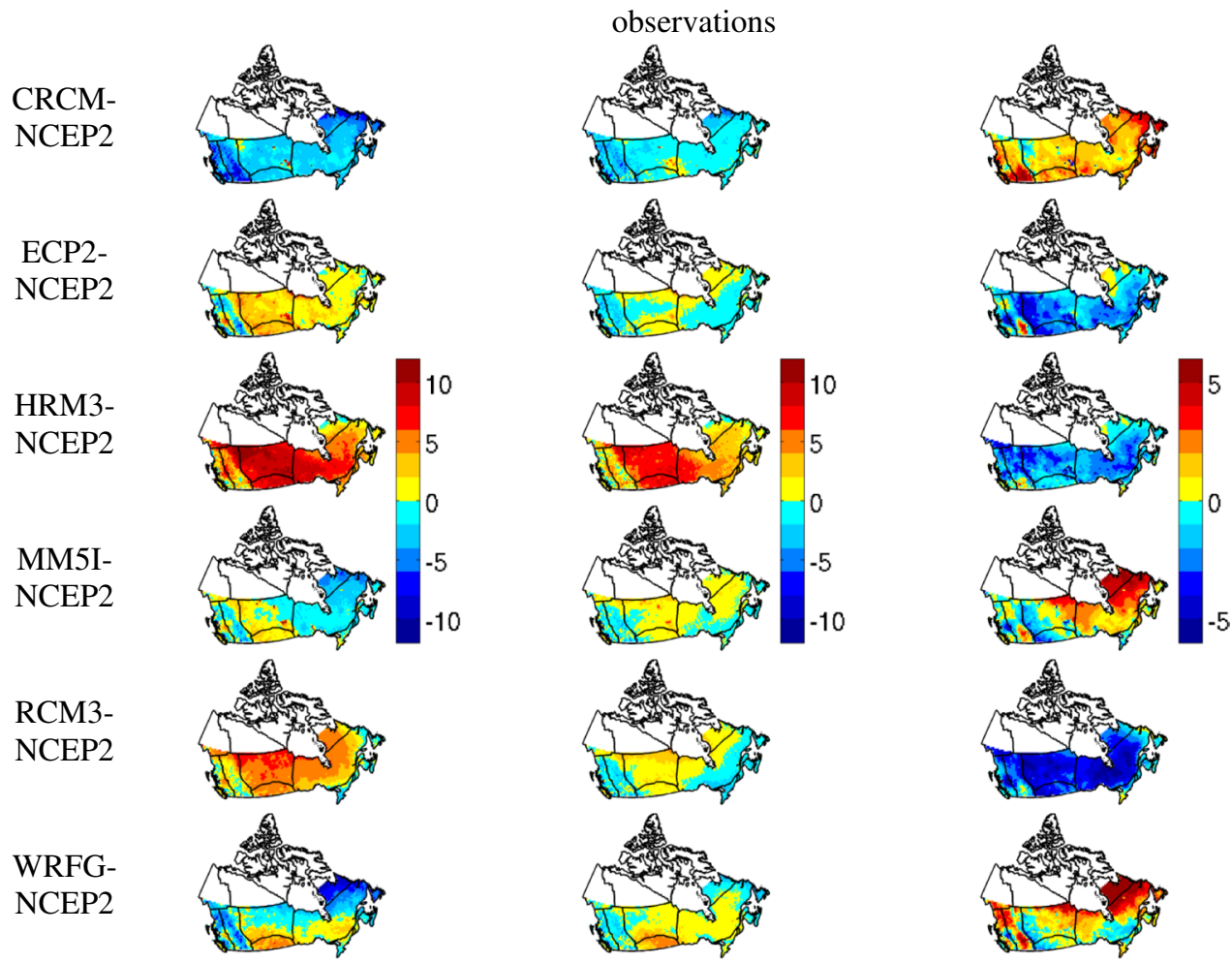

Fig. 2 Observed mean values of $\mathrm{T}_{\min }, \mathrm{T}_{\max }$, and DTR (top row) and differences of the same statistics between RCM-NCEP2s and observations for the winter (December to March) 1981 to 2003 period (rows 2-7) 
Fig. 3 Time series of spatial averages of the number of cold nights for each winter obtained from observed data and RCM-NCEP2s for seven southern Canadian climatic regions for the 1981-2003 period. For each winter, year on the $\mathrm{x}$-axis represents the year of the last three winter months (January, February, and March). The shaded area represents the range of the RCM-NCEP2s

\subsection{Frequency analysis of annual maxima}

Return values of maximum duration of cold spells for selected return periods, i.e., 10-, 20-, and 50-year, are estimated by the generalized extreme value (GEV) distribution. The GEV is theoretically the most suitable distribution for modeling block maxima (annual or seasonal maxima) (Hosking and Wallis 1997). Following suggestions from Hosking et al. (1985) for samples of small to medium size, which are 29 for the current and future period simulations in the present study, the method of probability weighted moments is used to estimate parameters of the GEV distribution, assuming time-slice stationarity. Additional detail about the GEV distribution and parameter estimation method can be found in Hosking and Wallis (1997).

\section{Results}

\subsection{Validation}

Prior to validating cold extremes indices, $\mathrm{T}_{\min }$ and $\mathrm{T}_{\max }$ series obtained from RCM-NCEP2s for the 1981-2003 period are evaluated. The aim of this validation exercise is to assess the errors associated with the physics and dynamics of the models, i.e., the performance errors. In Fig. 2, mean values of winter time $\mathrm{T}_{\min }, \mathrm{T}_{\max }$, and diurnal temperature range (DTR; difference between $T_{\min }$ and $T_{\max }$ ) for the RCM-NCEP $2 s$ are compared with those obtained from the observed dataset. The statistics for the three northern climatic regions (i.e., YUKON, MACK, and EARCT) are not shown in this figure as gridded observations are not available for these regions. The seven southern climatic regions are generally associated with mean values of $\mathrm{T}_{\min }$ lower than $0{ }^{\circ} \mathrm{C}$ in winter. The mean values of $\mathrm{T}_{\text {max }}$ for these regions are also lower than $0{ }^{\circ} \mathrm{C}$, except for the southern parts of the western coastal (WCOAST) and western cordillera (WCRDRA), Canadian Maritimes (MRTMS), and Great Lakes (GRTLKS) regions. Larger mean values of DTR in the range of $2-6^{\circ} \mathrm{C}$ are noted over the western parts of NWFOR and eastern parts of NEFOR. DTR is dependent on a number of factors such as the land surface state and elevation and therefore net shortwave radiation, cloud cover, etc. For instance, the DTR is
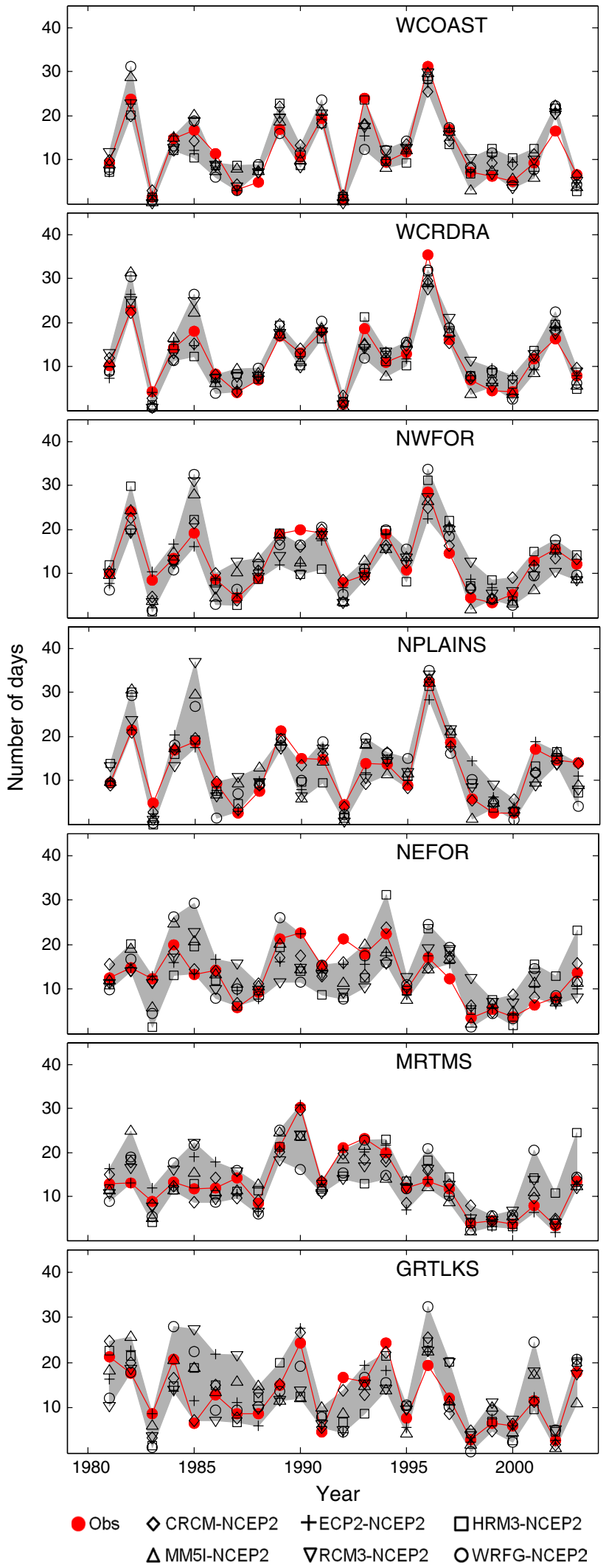
generally positively correlated with shortwave radiation and elevations, whereas it is negatively correlated with cloud cover and soil moisture (Jackson and Forster 2010).

The biases in $\mathrm{T}_{\min }$ are generally larger compared to those in $\mathrm{T}_{\max }$. These biases are generally in the -4 to $+6{ }^{\circ} \mathrm{C}$ range for $\mathrm{T}_{\text {min }}$ mean, -3 to $+4{ }^{\circ} \mathrm{C}$ range for $\mathrm{T}_{\max }$ mean, and -4 to $+4{ }^{\circ} \mathrm{C}$ range for DTR mean. Among the RCMs, generally, CRCM and HRM3 show systematic cold and warm biases, respectively, whereas ECP2 and RCM3 show predominantly a warm bias, particularly for $\mathrm{T}_{\min }$, for most of the southern climatic regions. MM5I and WRFG exhibit a large cold bias for $\mathrm{T}_{\text {min }}$ over northeastern Canada. ECP2, HRM3, and RCM3 underestimate the DTR as they generally have larger warm biases for $T_{\min }$ compared to $\mathrm{T}_{\max }$, whereas CRCM overestimates the DTR as it has a lager cold bias for $T_{\min }$ compared to $\mathrm{T}_{\max }$. Despite the above mentioned biases, the RCM-NCEP2s reproduce spatial patterns of observed $\mathrm{T}_{\text {min }}$ and $\mathrm{T}_{\max }$ mean values fairly well. For instance, spatial correlation coefficients of $T_{\min }$ mean and $\mathrm{T}_{\max }$ mean between observations and simulations for southern Canada are in the range of 0.89-0.97 and $0.85-0.94$, respectively.

The inter-annual variability of the number of cold nights for the RCM-NCEP2s is compared to those obtained from observations for seven climatic regions in Fig. 3. The inter-annual variability is generally larger for the western-central climatic regions compared to the eastern climatic regions. Cold season atmospheric circulation patterns are quite different for western and eastern North America. El Niño-La Niña/Southern Oscillation (ENSO), Pacific North American (PNA) pattern, and Pacific Decadal Oscillation (PDO) are closely linked to the variability in winter temperatures over the western Canadian regions, whereas the North Atlantic Oscillation (NAO) and the Arctic Oscillation (AO) have an impact on the variability in winter temperatures over the eastern Canadian regions (Prowse et al. 2011). The year 1996, which was one of the most severe winters in the region (Environment Canada 1996), is reproduced well by the RCM-NCEP2s, which is clearly visible in the plots for western-central regions (i.e., WCOAST, WCRDRA, NWFOR, and NPLAINS). Similarly, the year 1994, which was one of the coldest winter recorded over many parts of the northeast and north-central United States, as well as southern Canada (Assel et al. 1996), is reproduced well by the RCM-NCEP2s, particularly over the NEFOR and GRTLKS regions. The RCMNCEP2s, in general, display better performance for the western-central climatic regions compared to the eastern climatic regions, which is possibly due to the higher interannual variability of $\mathrm{T}_{\min }$ for the western-central climatic regions compared to the eastern climatic regions. Analyses of cold days show basically similar characteristics as the cold nights (not shown).
Figure 4 presents observed average number of frost days and ice days and those from the RCM-NCEP2s for the 1981-2003 period. According to observed data, the number of frost days is almost close to the total number of days of the winter period (i.e., 121 days in this study) for most regions, except for the south-western part of WCOAST, eastern part of MRTMS, and most part of GRTLKS. The observed number of ice days, on the other hand, exhibits a wider range (50-120 days). The southwestern and eastern coastal regions of Canada and GRTLKS generally display smaller than 60 days for the number of ice days as the mean values of $\mathrm{T}_{\max }$ for these regions are already larger than the absolute threshold of $0{ }^{\circ} \mathrm{C}$. The number of frost days and ice days for the RCM-NCEP2s, however, are directly affected by the biases of $\mathrm{T}_{\min }$ and $\mathrm{T}_{\max }$ simulations as they are identified based on the absolute temperature threshold. For instance, CRCM (HRM3) overestimates (underestimates) the number of observed frost days and ice days over many parts of southern Canada. Similarly, ECP2, RCM3, and WRFG tend to underestimate the number of frost days over the NPLAINS region. These overestimations and underestimations are predominantly due to the overestimations and underestimations of $\mathrm{T}_{\min }$ and $\mathrm{T}_{\max }$ values for these regions (Fig. 2).

The cold spell characteristics of the RCM-NCEP2s (not shown) generally reproduce the corresponding observed patterns well when using $\mathrm{T}_{\text {min }}$ thresholds for each model

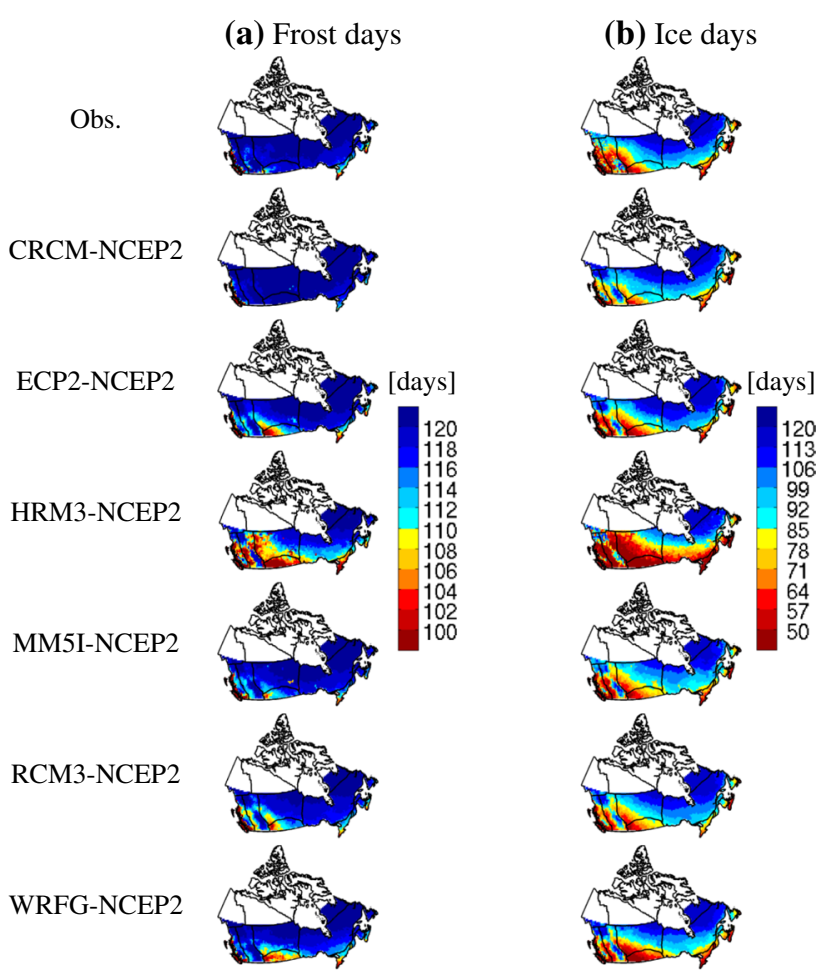

Fig. 4 Observed and RCM-NCEP2 simulated number of a frost days and $\mathbf{b}$ ice days per winter for the 1981-2003 period 


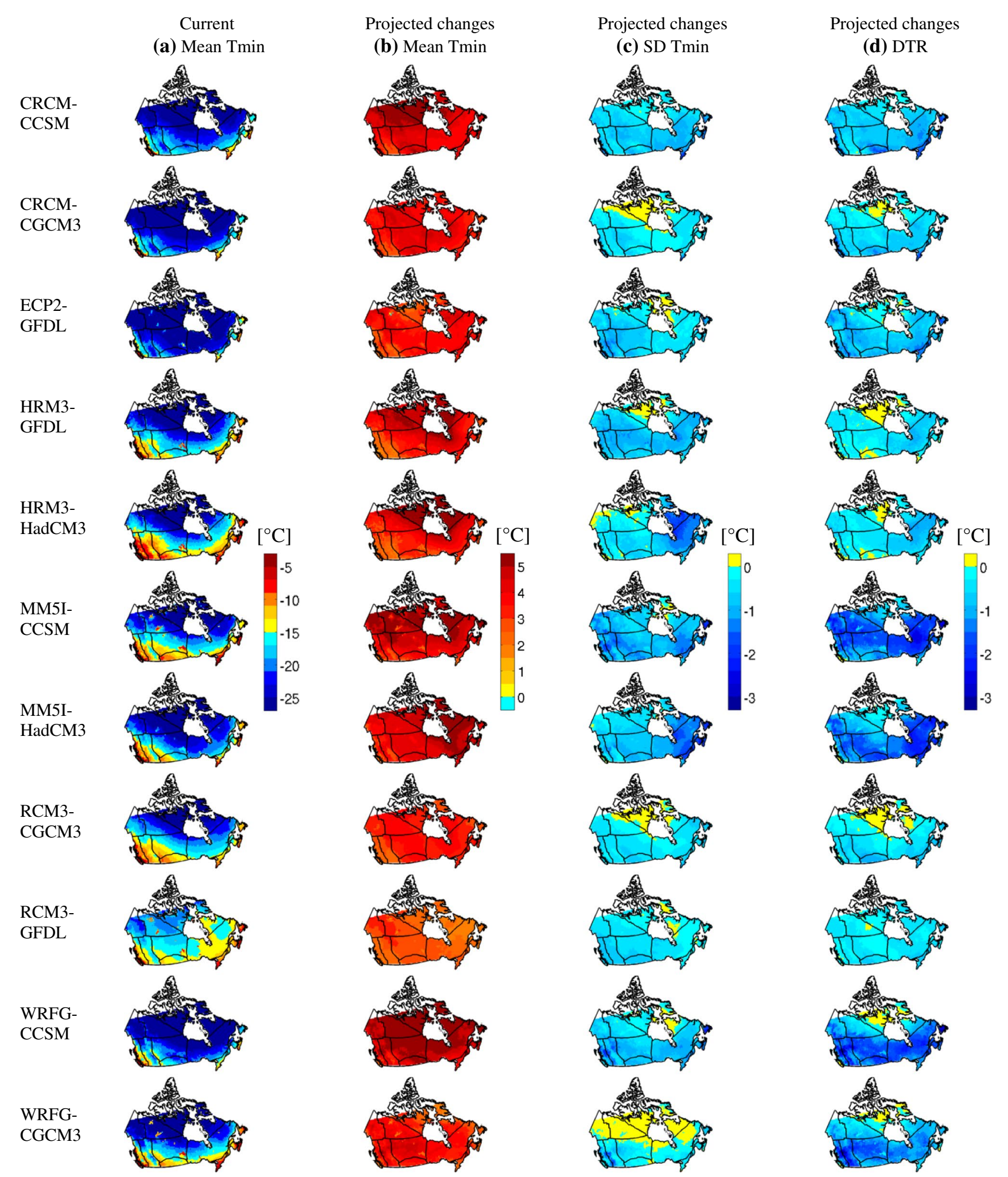

Fig. 5 a $\mathrm{T}_{\min }$ mean for the current 1970-1999 period and projected changes to $\mathbf{b} \mathrm{T}_{\text {min }}$ mean, $\mathbf{c}$ standard deviation (SD) of $\mathrm{T}_{\min }$, and $\mathbf{d} \mathrm{DTR}$ mean for winter for the future 2040-2069 period, with respect to the current 1970-1999 period, for various RCM-AOGCM combinations 
calculated from the simulated $\mathrm{T}_{\min }$ series of the corresponding model.

Among the 11 RCM-AOGCMs, $\mathrm{T}_{\min }$ values for CRCM-CCSM, CRCM-CGCM3, and ECP2-GFDL are cooler compared to those for HRM3-HadCM3, MM5ICCSM, RCM3-CGCM3 and RCM3-GFDL (left column in Fig. 5). As shown in Fig. 2, CRCM-NCEP2 and HRM3NCEP2 show cold and warm biases in $\mathrm{T}_{\text {min }}$ for the validation period. Similar biases are also observed in simulations driven by AOGCMs. Thus, the boundary forcing errors, i.e. the differences associated with the AOGCM boundary forcing data, reflected in the differences between RCM simulations driven by NCEP2 and those driven by AOGCMs, are generally smaller than the performance errors.

\subsection{Projected changes}

The projected changes to $\mathrm{T}_{\min }$ and $\mathrm{T}_{\max }$ and also to cold extreme days and cold spells for the future 2040-2069 period, with respect to the current 1970-1999 period, based on the 11 RCM-AOGCMs, are discussed here. The projected changes to the $\mathrm{T}_{\text {min }}$ mean and standard deviation (SD) and DTR are presented in Fig. 5. The RCMAOGCMs suggest an increase in the $T_{\text {min }}$ mean, which is generally larger than $2{ }^{\circ} \mathrm{C}$. Spatially, the RCM-AOGCMs tend to project smaller increases in $\mathrm{T}_{\min }$ over the southwestern climatic regions (i.e., WCOAST, WCRDRA, and NPLAIN) compared to the other regions. The projected changes in the $\mathrm{T}_{\min }$ mean exhibit higher spatial variability among the 11 RCM-AOGCMs, particularly over the central and eastern climatic regions. Among the RCMAOGCMs, CCSM driven simulations (i.e., CRCM-CCSM, MM5I-CCSM, and WRFG-CCSM) show a larger increase in $\mathrm{T}_{\min }$ compared to the other simulations. RCM3-GFDL, on the other hand, shows the smallest increase. These results highlight the influence of the driving fields on RCM projections.

The RCM-AOGCMs generally show a decrease in the $\mathrm{SD}$ of $\mathrm{T}_{\text {min }}$, which could result in decreased frequency and severity of cold nights and cold spells in the future because the frequency and severity of cold extreme events are affected considerably by changes in the variability of $T_{\min }$. The RCM-AOGCMs also indicate a decrease in the DTR because $\mathrm{T}_{\min }$ increases more than $\mathrm{T}_{\max }$ in the future.

Figure 6 presents projected changes to the number of cold nights and cold days. In the figure, projected changes are shown on the basis of the driving AOGCM (in columns) and RCM (in rows) in order to assess the uncertainties associated with model formulation and those associated with the large-scale boundary forcing. The former (latter) uncertainties, referred to generally as structural (driving AOGCM related) uncertainties, can be assessed by comparing figures

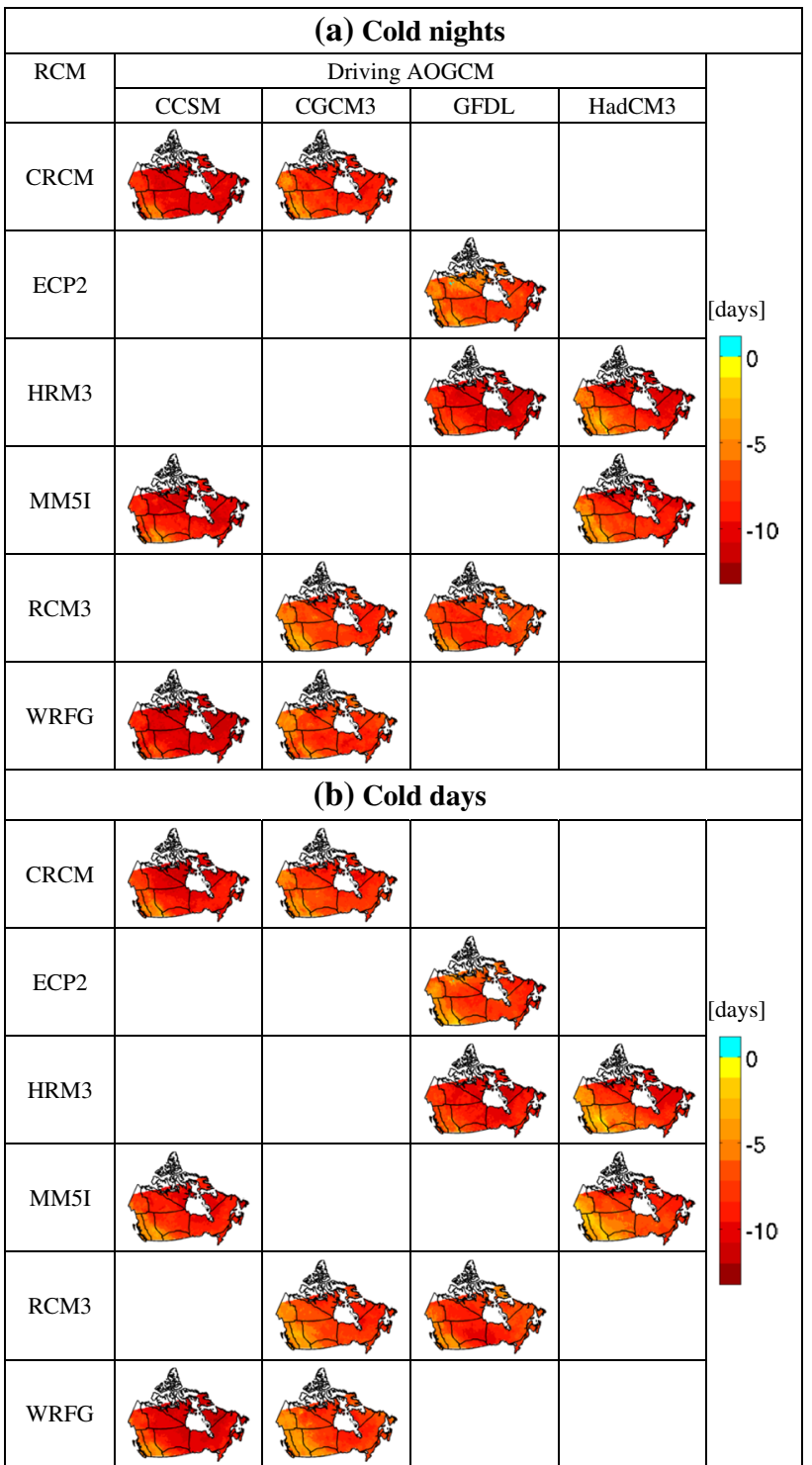

Fig. 6 Projected changes to the number of a cold nights and $\mathbf{b}$ cold days per winter for the future 2040-2069 period, with respect to the current 1970-1999 period, for various RCM-AOGCM combinations

in the column (row) corresponding to the same AOGCM (RCM). The number of cold nights and cold days for the current period are not provided as they are usually $10 \%$ of the total number of days in winter (i.e., 12 days) according to their definitions. All RCM-AOGCMs suggest a decrease in the number of cold nights and cold days for all Canadian climatic regions in the future. The decreases are found statistically significant at the $10 \%$ significance level based on the two-sample $t$ test. The projected changes, however, are spatially inconsistent with each other as they are dependent on the model formulation and physical parameterization schemes of the respective RCM and also on the large-scale boundary forcing, i.e., the driving AOGCM. For example, 

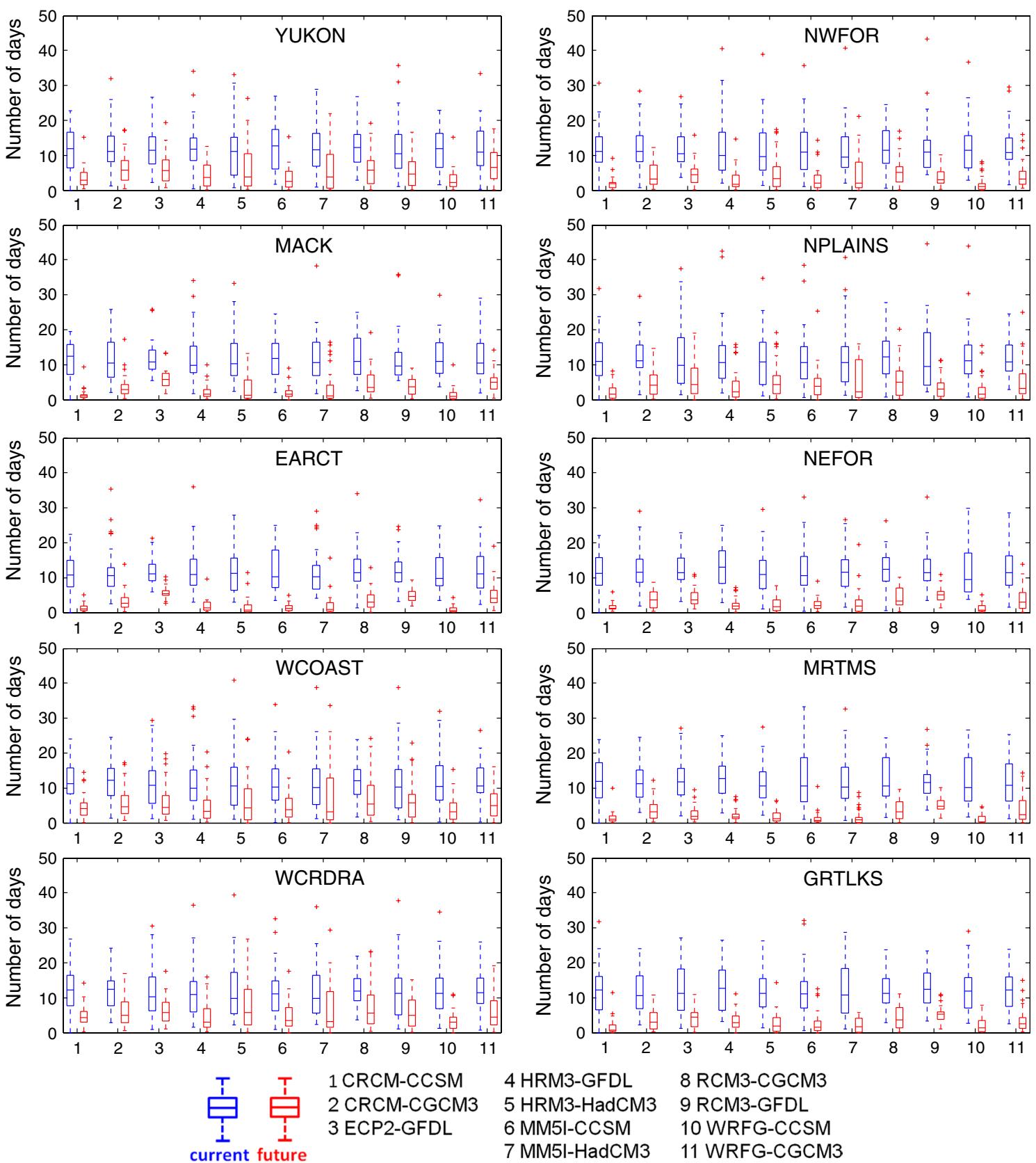

Fig. 7 Box and whisker plots of spatial averages of the number of cold nights for each winter obtained from all RCM-AOGCMs for the ten Canadian climatic regions for the current (1970-1999) and future (2040-2069) periods. The box and whisker plot displays minimum,

lower quartile (LQ), median, upper quartile (UQ), and maximum values. Outliers are identified when a value falls below LQ $-1.5 \times \mathrm{IQR}$ or above $\mathrm{UQ}+1.5 \times \mathrm{IQR}$, where IQR is the inter quartile range

projected changes to the number of cold nights and cold days and their spatial distributions are quite different for ECP2-GFDL, HRM3-GFDL, and RCM3-GFDL, which are driven by the same AOGCM, suggesting that these differences could be related to differences in parameterization schemes of the RCMs. Projected changes to the number of cold nights and cold days also show differences for the same RCM, with different boundary forcing. Spatially, the

RCM-AOGCMs tend to project smaller decrease in the number of cold nights for the western climatic regions (i.e., YUKON, WCOAST, WCRDRA, and NPLAIN) as they generally suggest smaller increases in $\mathrm{T}_{\min }$ for these regions compared to the other regions as shown in Fig. 5. The spatial distribution of RCM-AOGCM simulated number of cold days are similar to those of cold nights, but the projected decreases in the number of cold days are generally 1 
Fig. 8 Projected changes to the number of freeze-thaw days per winter for the future 2040-2069 period, with respect to the current 1970-1999 period, for various RCM-AOGCM combinations. Grid points are colorless if the projected changes are not statistically significant at the $10 \%$ significance level, based on the two-sample $t$ test

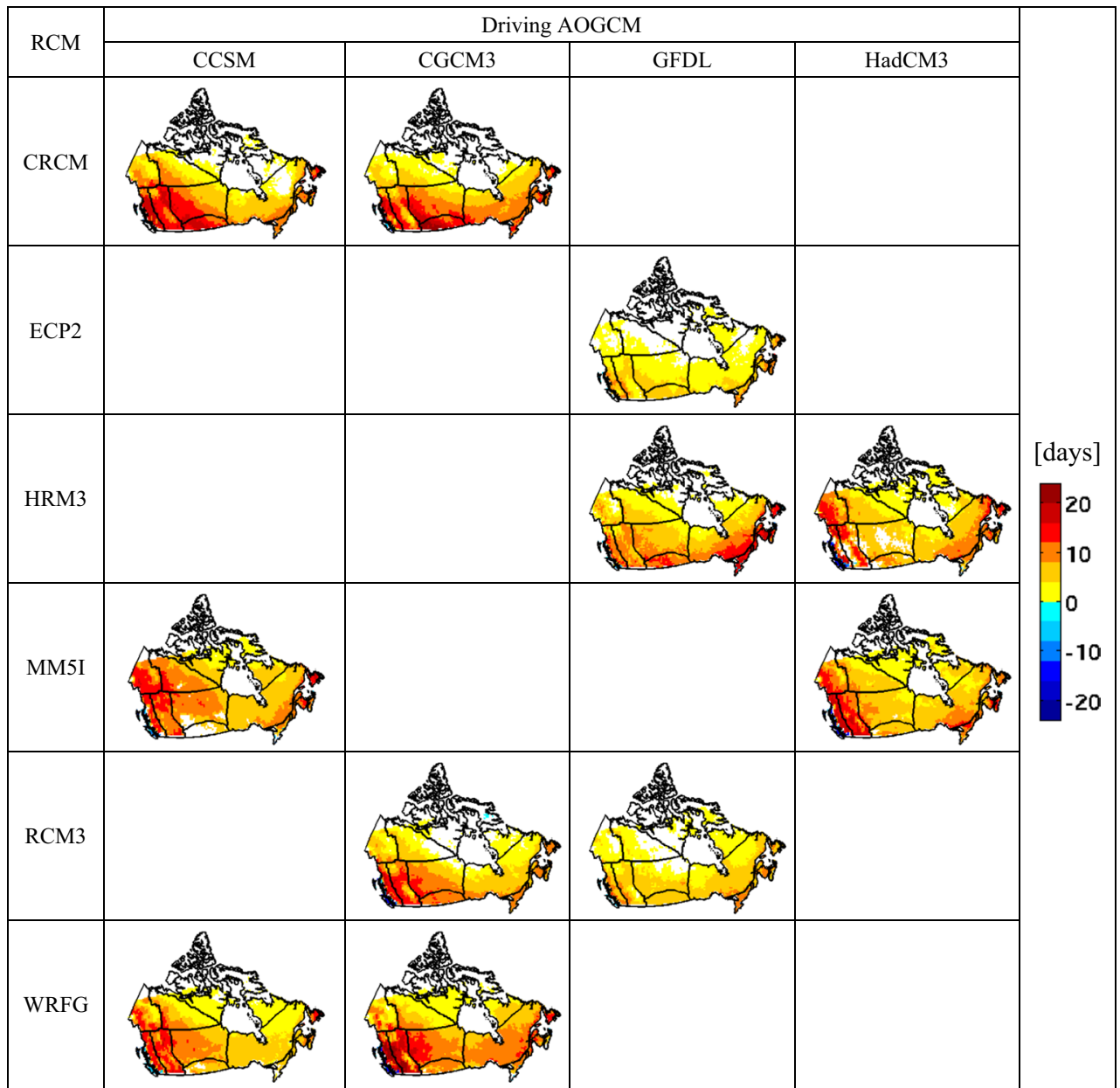

or 2 days smaller than those of cold nights as $\mathrm{T}_{\text {min }}$ increases more than $\mathrm{T}_{\max }$ in the future period.

Box and whisker plots of spatial averages of the number of cold nights for the RCM-AOGCMs for both current and future periods for all ten climatic regions are shown in Fig. 7. The RCM-AOGCMs suggest a decrease in the number of cold nights for the future period for all regions. It is also obvious that these box plots exhibit smaller interannual variability in the future period compared to the current. The RCM-AOGCMs, however, suggest smaller decreases in the number of cold nights for some western climatic regions (i.e., YUKON, WCOAST, and WCRDRA) compared to the other regions.

The projected changes to the number of freeze-thaw days for the future 2040-2069 period, with respect to the current 1970-1999 period, are presented in Fig. 8. As shown in Fig. 5, $\mathrm{T}_{\min }$ and $\mathrm{T}_{\max }$ values of the RCMAOGCMs for the southern and coastal Canadian regions are generally higher than those for the northern Canadian regions in the current period and hence increases in $\mathrm{T}_{\min }$ and $\mathrm{T}_{\max }$ suggest larger decreases in the number of frost days and ice days for southern Canada compared to northern regions (not shown). The RCM-AOGCMs also suggest larger decreases in the number of ice days than the number of frost days as increases in the $T_{\max }$ values imply frequent exceedances of the absolute threshold of $0{ }^{\circ} \mathrm{C}$ than the $\mathrm{T}_{\text {min }}$ values in the future period (not shown). Among the model simulations, CRCM-CCSM, CRCMCGCM3, and ECP2-GFDL, which show cold biase in $\mathrm{T}_{\text {min }}$ for the current period, tend to underestimate the number of frost days compared to the other simulations. If a particular RCM-AOGCM simulation has a cold bias in the current period, the future increase in the $\mathrm{T}_{\min }$ series could be more difficult to reach the fixed threshold (i.e., $0{ }^{\circ} \mathrm{C}$ ) compared to another RCM-AOGCM simulation with an unbiased projection. Consequently, the RCM-AOGCMs suggest a significant increase in the number of freezethaw days for southern and coastal Canadian regions for the future period (Fig. 8). Among the RCM-AOGCMs, ECP2-GFDL and RCM3-GFDL simulations (the fromer shows cold biase in $\mathrm{T}_{\min }$ and the latter shows the smallest increase in $\mathrm{T}_{\min }$ for the future period) tend to underestimate the number of freeze-thaw days compared to the other simulations. 
Fig. 9 Regional averages of observed and RCM-AOGCM simulated number of cold spell events with respect to different duration thresholds for the current 1970-1999 period (left column) and projected changes to the same statistic (right column) for selected seven Canadian climatic regions (i.e., YOKON, WCOAST, WCRDRA,

NPLAINS, NEFOR, MRTMS, and GRTLKS). Observed values for YOKON are not shown as gridded observations are not available for this region (a) Cold spell events (current)
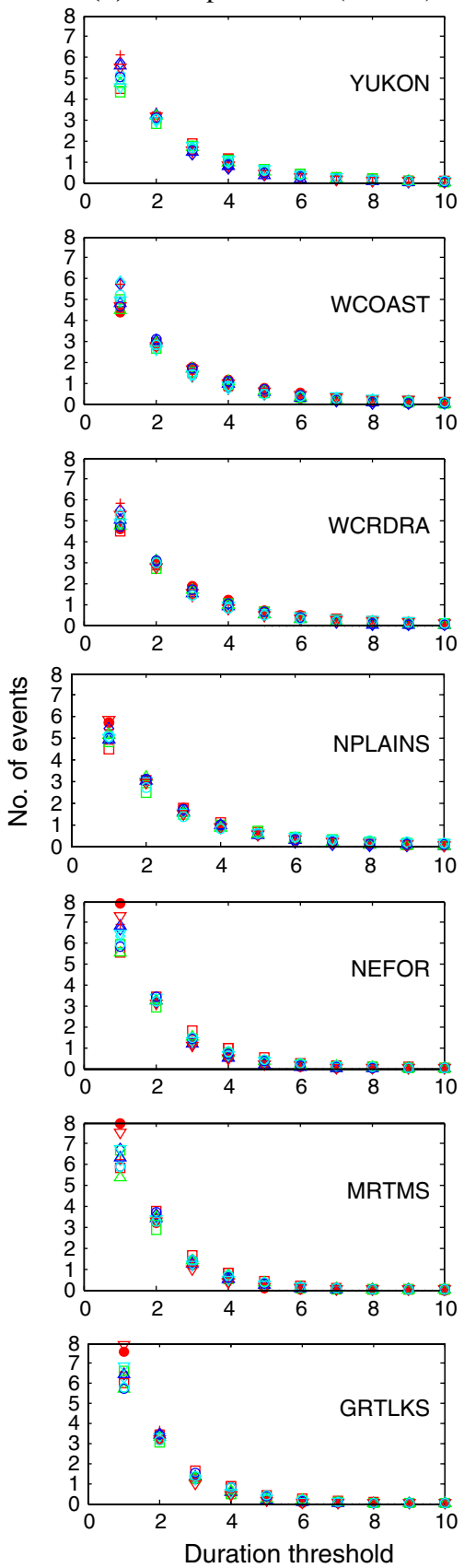

(b) Projected changes
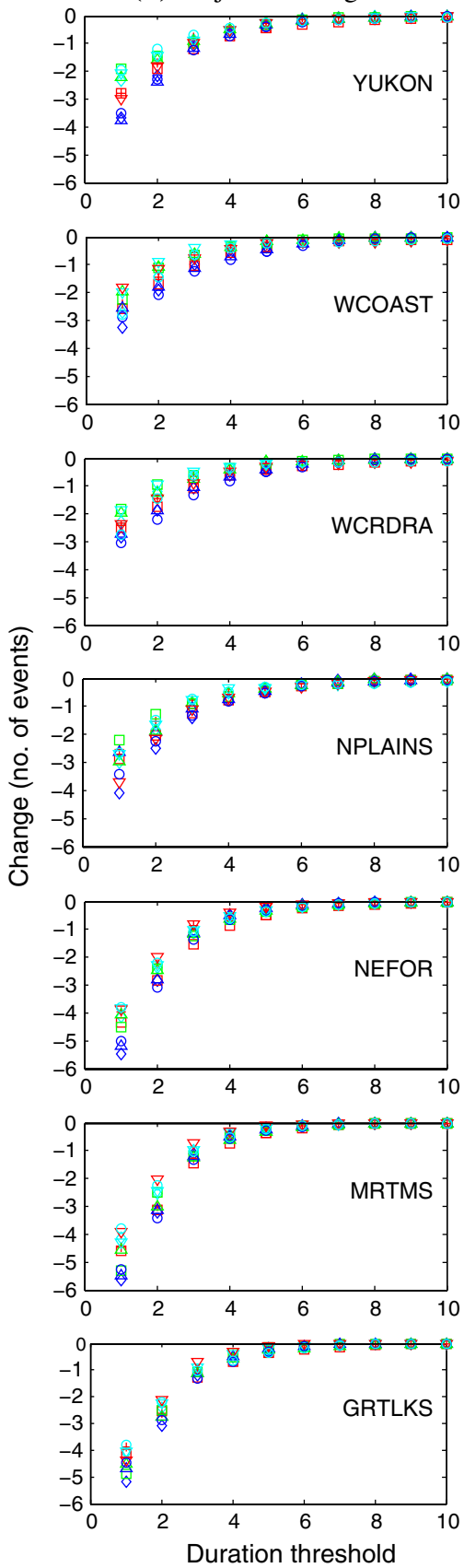

$\Delta$ MM5I-CCSM $\nabla$ RCM3-CGCM3 O WRFG-CCSM $\triangle$ MM5I-HadCM3 $\nabla$ RCM3-GFDL O WRFG-CGCM3
Figure 9 presents observed and simulated average number of cold spell events with respect to different duration thresholds for the current 1970-1999 period and its projected changes for the future 2040-2069 period for selected western (i.e. YUKON, WCOAST, WCRDRA, and NPLAINS) and eastern (i.e. NEFOR, MRTMS, and GRTLKS) climatic regions. All simulations yield about similar average number of cold spell events for the current period, which is certainly due to applying $\mathrm{T}_{\min }$ threshold calculated from the simulated $\mathrm{T}_{\min }$ series. All simulations suggest decreases in the number of cold spell events in the future, with the projected changes being larger for the eastern regions. Among the simulations, those driven by CCSM (i.e., CRCM-CCSM, MM5I-CCSM, and WRFG-CCSM) suggest relatively larger decreases as they project larger increases in $\mathrm{T}_{\min }$ compared to the other simulations (Fig. 5).

Figure 10 presents projected changes to the number of cold spells for the future 2040-2069 period, for 3-day 


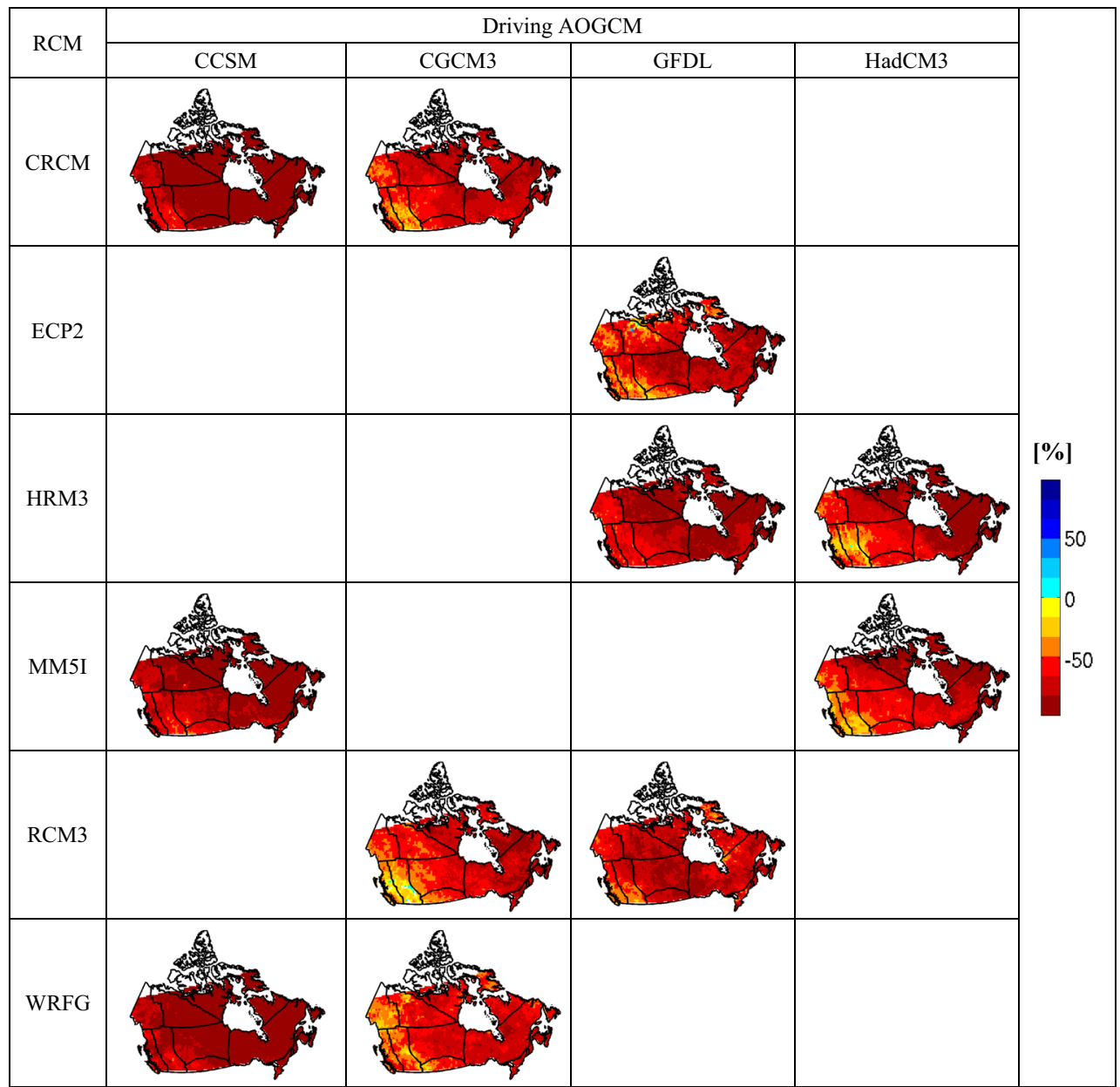

Fig. 10 Projected changes to the number of cold spell events as simulated by various RCM-AOGCM combinations for 3-day duration threshold

duration threshold. The spatial patterns of projected changes are basically similar to those for the number of cold nights shown in Fig. 6. Again, CCSM driven simulations (i.e., CRCM-CCSM, MM5I-CCSM, and WRFGCCSM) generally show larger decreases in the number of cold spell events compared to the other simulations, due to the larger increase in the future $\mathrm{T}_{\min }$ values (Fig. 5). The decreases in the number of cold spells are found statistically significant at the $10 \%$ significance level in all cases, based on the two-sample $t$ test.

In Fig. 11, observed and simulated 10-, 20-, and 50-year return levels of maximum cold spell duration for the current 1970-1999 period and their projected changes for the future 2040-2069 period are shown for selected climatic regions. The return levels are in general larger for the western climatic regions compared to the eastern regions, for the current period, which is consistent with the variability of the number of cold nights. As shown in Figs. 3 and 7, western climatic regions have larger inter-annual variability for the number of cold nights, which can result in higher return levels of maximum duration of cold spells compared to the eastern climatic regions. Again the RCM-AOGCMs generally suggest a decrease in return levels for all climatic regions in the future, with the projected changes being larger for eastern regions. The changes, however, display smaller decreases for return levels of longer return periods (e.g., 50-year) compared to those of shorter return periods (e.g., 10-year).

\section{Discussion and conclusions}

Projected changes to cold extreme days (i.e., cold nights, cold days, frost days, and ice days) and cold spells for the winter (DJFM) period over Canada, for the future 2040 2069 period with respect to the current 1970-1999 period, are investigated based on multi-RCM simulations available through NARCCAP. These simulations were obtained with six different RCMs and four different driving AOGCMs for the SRES A2 scenario. For assessing performance of 
Fig. 11 Regional averages of observed and RCM-AOGCM simulated 10-, 20-, and 50-year return levels of maximum duration of cold spells for the current 1970-1999 period (left column) and projected changes to the same return levels (right column) for selected seven Canadian climatic regions (i.e., YOKON, WCOAST, WCRDRA, NPLAINS, NEFOR, MRTMS, and GRTLKS). Observed values for YOKON are not shown as gridded observations are not available for this region (a) Return levels (current)
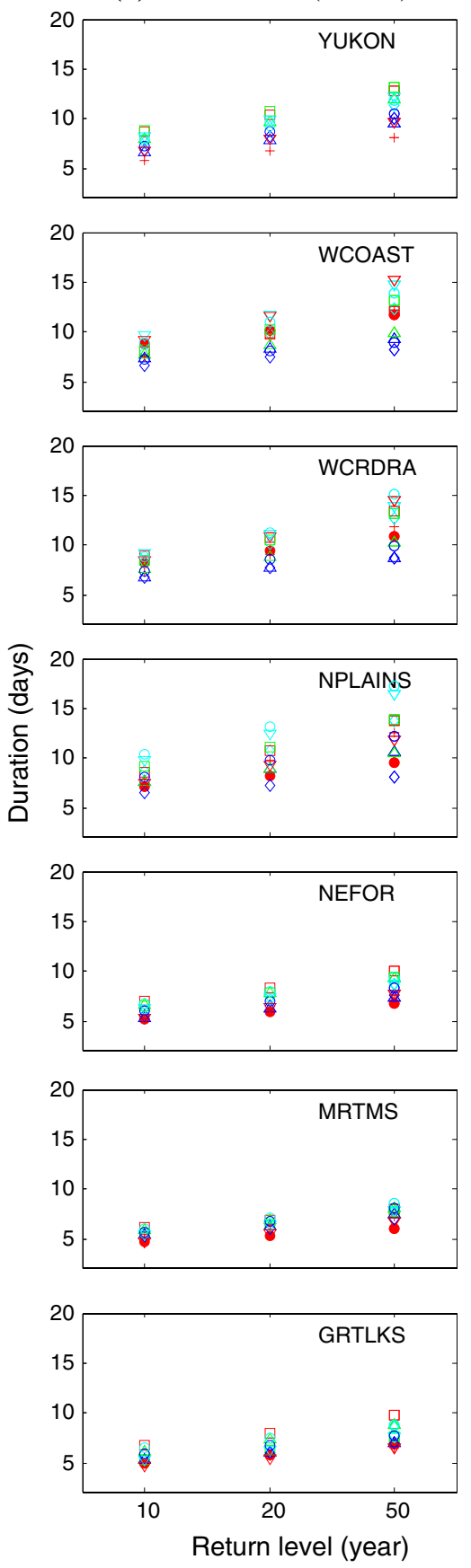

Obs $\triangle$ CRCM-CCSM + ECP2-GFDL $\square$ HRM3-GFDL $\triangle \mathrm{CRCM}-\mathrm{CGCM} 3$ (b) Projected changes
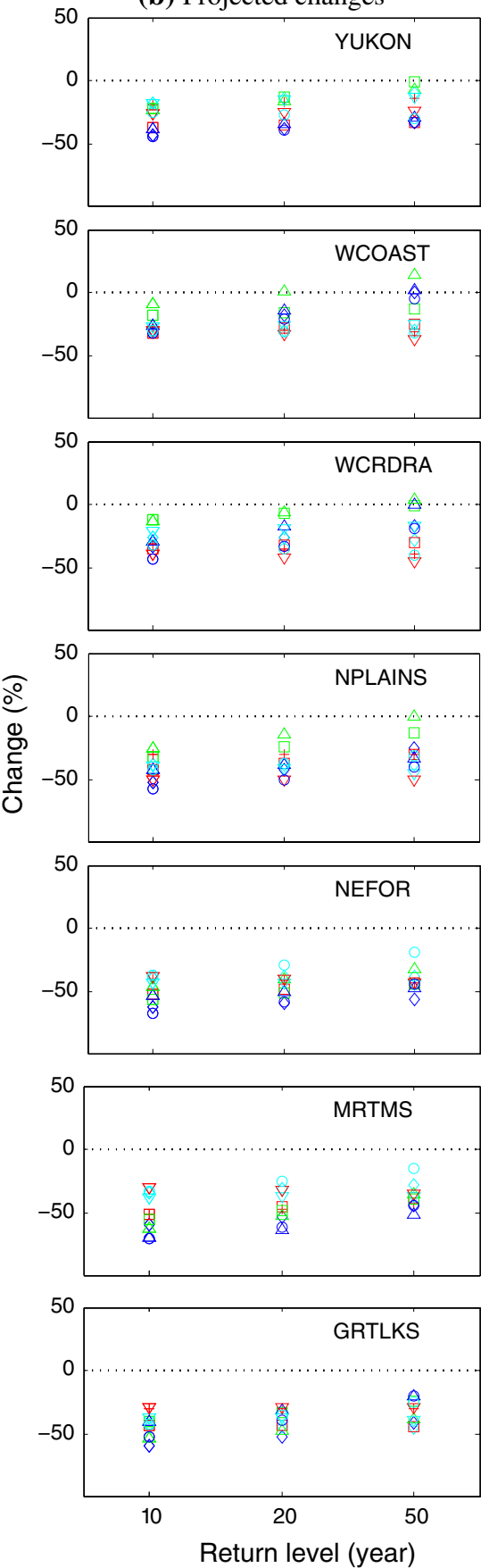

Return level (year)

$\Delta$ MM5I-CCSM $\nabla$ RCM3-CGCM3 O WRFG-CCSM

$\square$ HRM3-HadCM3 $\triangle$ MM5l-HadCM3 $\nabla$ RCM3-GFDL O WRFG-CGCM3 these RCMs, NCEP2 driven simulations for the 19812003 period are evaluated. This evaluation suggests that these RCMs are able to reproduce observed spatial patterns of the climatology of $\mathrm{T}_{\text {min }}$ and $\mathrm{T}_{\max }$ and inter-annual variability in the number of cold days and nights over different climatic regions of Canada. It is noted that model biases directly affect the model performance in reproducing frost and ice days, which are identified using an absolute temperature threshold $\left(0{ }^{\circ} \mathrm{C}\right)$. These biases, however, do not affect significantly their ability in reproducing cold nights, cold days, and cold spells, which are identified using local temperature thresholds of each model calculated from the simulated $\mathrm{T}_{\min }$ and $\mathrm{T}_{\max }$ series of the same model.

The projected changes to the number of cold nights, cold days, frost days and ice days for various climatic regions are summarized in Fig. 12. The RCM-AOGCMs 


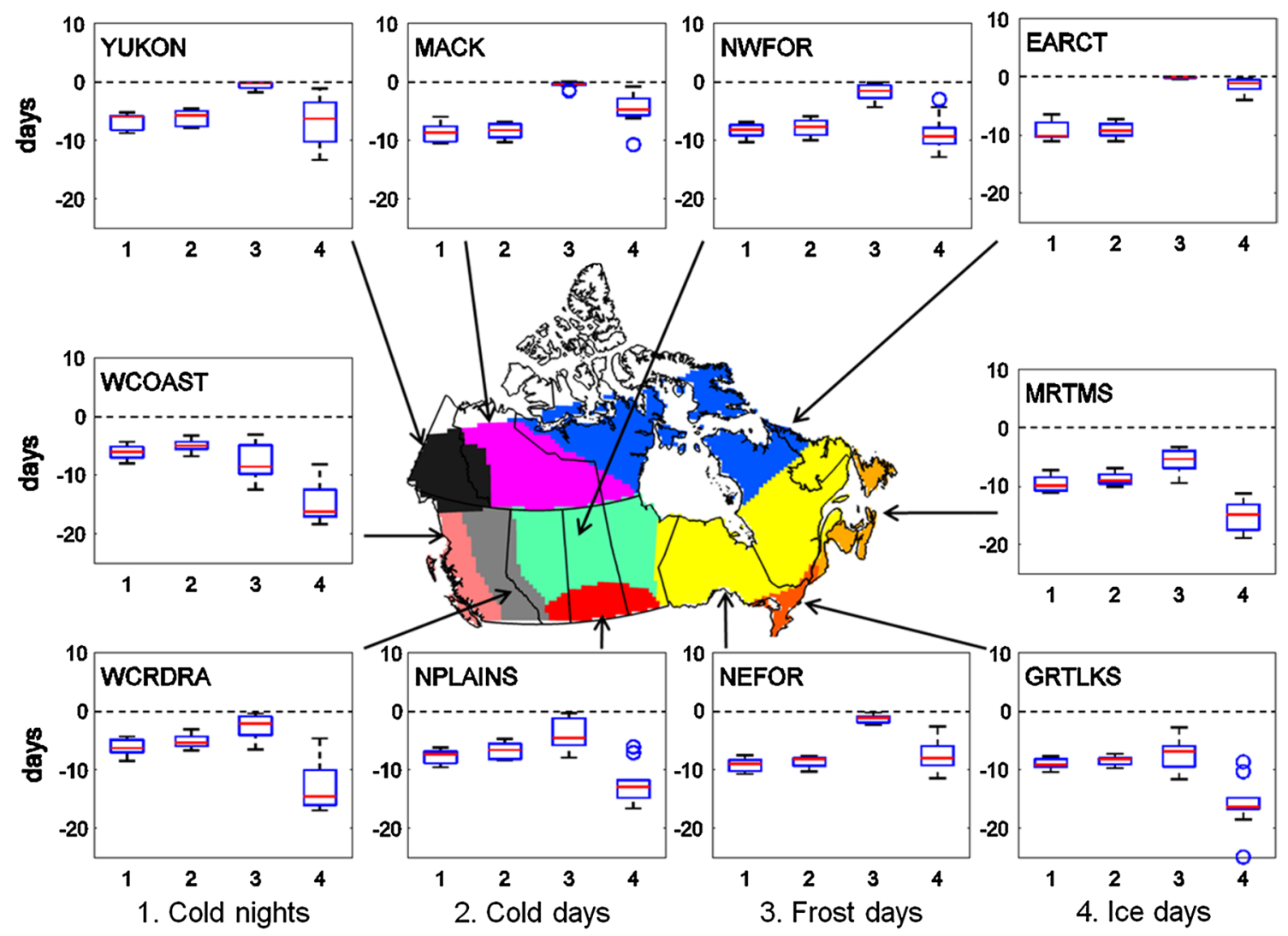

Fig. 12 Box and whisker plots of regional projected changes to cold nights, cold days, frost days and ice days per winter based on 11 RCM-AOGCMs for the future 2040-2069 period, with respect to the

suggest an overall decrease in the number of cold extreme events (i.e., cold nights, cold days and cold spells) for all climatic regions for the future period. Results also suggest that the number of cold nights will decrease more than the number of cold days, as $T_{\text {min }}$ increases more than $\mathrm{T}_{\max }$ in future period compared to the current. The RCM-AOGCMs also suggest a decrease in the return values of maximum duration of cold spells. Future decreases in the frequency of cold temperature extremes can reduce cold-related fatalities in the future. For instance, Cheng et al. (2007) suggested that coldrelated mortality could decrease by more than $40 \%$ in southern Ontario and Quebec by 2050, based on future scenarios of five general circulation models. On the other hand, favorable temperature during winter for insect species due to less frequent cold temperature extremes could lead to increased risk from vector-borne diseases in the future, which are already observed in the northern Canadian regions (Parkinson and Butler 2005). The RCMAOGCMs suggest smaller decreases in the number of cold extreme events over western climatic regions (i.e., YUKON, WCOAST, WCRDRA, and NPLAINS) compared to the other regions. current 1970-1999 period. Description of the box and whisker plot is given in Fig. 7

The RCM-AOGCMs suggest an increase in the frequency of mid-winter freeze-thaw events as they project overall decreases in the number of frost days and ice days. The number of ice days is expected to decrease by a larger margin compared to the number of frost days, and southern climatic regions are expected to witness a larger decrease than the northern climatic regions in both indices. It is noted that cold biases of RCMs (e.g. CRCMCCSM, CRCM-CGCM3, and ECP2-GFDL) could result in underestimation of the projected changes in the frequency of frost and ice days. The decrease will be more intense over the southern climatic regions than the northern climatic regions for the two absolute threshold indices. These decreases in cold extreme events can lead to some negative impacts. For instance, the increased frequency of midwinter freeze-thaw events could lead to several natural hazards such as snow slides and avalanches (Nickels et al. 2006), landslides, erosion of clayey slopes and friable sandstone cliffs (Bernatchez and Dubois 2004), ice jam (Beltaos and Prowse 2001), and rain-on-snow flooding (Catto and Hickman 2004). All of the above could create significant damages over the densely populated southern and coastal Canadian regions. 
Increased temperatures and decreased number of cold extreme events in winter also could result in positive and negative impacts on socioeconomic activities in the future. Increased winter temperatures could benefit the energy sector due to decreased energy demand for heating (Klaassen 2003). For the transportation sector, decrease in the number of frost and ice days could result in reduced costs associated with snow removal and road management. With reduced winter ice cover, marine and river shipping could become more important for the transportation of goods and services and will reduce icebreaking costs in the future (Millerd 2005). On the other hand, decreases in the thickness and duration of lake and river ice could significantly affect the viability of many winter road networks, which are providing access to remote communities and mine and forest sites in northern Canada (Lemmen et al. 2008). Winter warming will create longer growing season, which could increase agricultural and forestry productivity and allow cultivate potentially more profitable crops and tree species in the future. Decreases in the number of frost and ice days can lead to changes in the duration and distribution of snow, which could impact winter recreational activities, such as snowmobiling and skiing, especially in southern Canada.

The projected changes derived in this study, based on high-resolution RCMs driven by different AOGCMs, are useful to evaluate detailed regional impacts on different social, economic, and environmental sectors. This study briefly discussed the negative and positive effects of the future warm winter on various sectors of Canada. However, more detailed studies are necessary to facilitate appropriate adaptation strategy, especially for the highly populated southern and costal Canadian regions, as these regions are clearly expected to experience less frequent cold extreme events and more frequent freeze-thaw events in the future winter according to the results presented. A bias correction procedure might be useful for RCM outputs, particularly to quantify projected changes to the number of frost and ice days, as model biases can affect these extreme days. In addition, the current study focused only on the SRES A2 emission scenario, and a broader set of emission scenarios might be necessary to evaluate uncertainties in the future projections of cold extreme days and cold spells.

Acknowledgments The authors thank the North American Regional Climate Change Assessment Program for the multi-RCM simulated data used in the study. This research was undertaken within the framework of the Canadian Network for Regional Climate and Weather Processes, funded by the Natural Sciences and Engineering Research Council of Canada.
Open Access This article is distributed under the terms of the Creative Commons Attribution 4.0 International License (http://creativecommons.org/licenses/by/4.0/), which permits unrestricted use, distribution, and reproduction in any medium, provided you give appropriate credit to the original author(s) and the source, provide a link to the Creative Commons license, and indicate if changes were made.

\section{References}

Assel RA, John EJ, Sharolyn Y, Daron B (1996) Winter 1994 weather and ice conditions for the Laurentian Great Lakes. Bull Am Meteorol Soc 77:71-88

Beltaos S, Prowse TD (2001) Climate impacts on extreme ice-jam events in Canadian rivers. Hydrol Sci J 46(1):157-181

Beniston M, Stephenson DB, Christensen OB, Ferro CA, Frei C, Goyette S, Halsnaes K, Holt T, Jylhä K, Koffi B, Palutikof J, Schöll R, Semmler T, Woth K (2007) Future extreme events in European climate: an exploration of regional climate model projections. Clim Change 81(1):71-95

Bernatchez P, Dubois JMM (2004) Bilan des connaissances de la dynamique de l'érosion des côtes du Québec maritime laurentien. Géog Phys Quatern 58(1):45-71

Catto NR, Hickman H (2004) Flood hazard and vulnerability in Newfoundland communities. Office of Critical Infrastructure and Emergency Preparedness Canada, Newfoundland

Caya D, Laprise R (1999) A semi-implicit semi-Lagrangian regional climate model: the Canadian RCM. Mon Weather Rev 127:341-362

Cheng CS, Campbell M, Li Q, Li G, Auld H, Day N, Pengelly D, Gingrich S, Yap D (2007) A synoptic climatological approach to assess climatic impact on air quality in south-central Canada. Part II: future estimates. Water Air Soil Pollut 182(1-4):117-130

Collins WD et al (2006) The community climate system model version 3 (CCSM3). J Clim 19:2122-2143

Environment Canada (1996) The top ten Canadian weather stories of 1996. http://ec.gc.ca/meteo-weather/default.asp?lang=En\&n=4 22C1B46-1

Fischer EM, Schär C (2010) Consistent geographical patterns of changes in high-impact European heatwaves. Nat Geosci 3(6):398-403

Flato GM (2005) The third generation coupled global climate model (CGCM3). http://www.ec.gc.ca/ccmac-cccma/default. asp? $\mathrm{n}=1299529 \mathrm{~F}-1$

Gamdt GFDL (2004) The new GFDL global atmospheric and land model AM2-LM2: evaluation with prescribed SST simulations. J Clim 17:4641-4673

Gordon C et al (2000) The simulation of SST, sea ice extents and ocean heat transports in a version of the Hadley Centre coupled model without flux adjustments. Clim Dyn 16:147-168

Grell GA, Devenyi DA (2002) Generalized approach to parameterizing convection combining ensemble and data assimilation techniques. Geophys Res Lett 29:1693-1697

Grell GA, Dudhia J, Stauffer DR (1993) A description of the fifthgeneration Penn State/NCAR Mesoscale Model (MM5). NCAR Tech. Note NCAR/TN-398+1A

Hopkinson RF, McKenney DW, Milewska EJ, Hutchinson MF, Papadopol P, Vincent LA (2011) Impact of aligning climatological day on gridding daily maximum-minimum temperature and precipitation over Canada. J Appl Meteorol Climatol 50(8):1654-1665 
Hosking JRM, Wallis JR (1997) Regional frequency analysis: an approach based on L-moments. Cambridge University Press, New York

Hosking JRM, Wallis JR, Wood EF (1985) Estimation of the generalized extreme-value distribution by the method of probability weighted moments. Technometrics 273:251-261

IPCC (2012) Managing the risks of extreme events and disasters to advance climate change adaptation. A special report of working groups I and II of the intergovernmental panel on climate change [Field CB, Barros V, Stocker TF, Qin D, Dokken DJ, Ebi KL, Mastrandrea MD, Mach KJ, Plattner G-K, Allen SK, Tignor M, Midgley PM (eds)]. Cambridge University Press, Cambridge, UK, and New York, NY, USA

IPCC (2013) Climate change 2013. The physical science basis. Contribution of working group I to the fifth assessment report of the intergovernmental panel on climate change [Stocker TF, Qin D, Plattner G-K, Tignor M, Allen SK, Boschung J, Nauels A, Xia Y, Bex V, and Midgley PM (eds)]. Cambridge University Press, Cambridge, UK and New York, NY, USA

Islam S, Rehman N, Sheikh MM (2009) Future change in the frequency of warm and cold spells over Pakistan simulated by the PRECIS regional climate model. Clim Change 94(1-2):35-45

Jackson LS, Forster PM (2010) An empirical study of geographic and seasonal variations in diurnal temperature range. J Clim 23(12):3205-3221

Jeong DI, St-Hilaire A, Ouarda TBMJ, Gachon P (2012) A multivariate multi-site statistical downscaling model for daily maximum and minimum temperatures. Clim Res 54:129-148

Jeong DI, St-Hilaire A, Ouarda TBMJ, Gachon P (2013) Projection of multi-site daily temperatures over the Montréal area, Canada. Clim Res 56:261-280

Jeong DI, Sushama L, Diro GT, Khaliq MN, Beltrami H, Caya D (2015) Projected changes to high temperature events for Canada based on a regional climate model ensemble. Clim Dyn. doi:10.1007/s00382-015-2759-y

Jones RG, Hassell DC, Hudson D, Wilson SS, Jenkins GJ, Mitchell JFB (2003) Workbook on generating high resolution climate change scenarios using PRECIS. UNDP, New York

Juang H-M, Hong S-Y, Kanamitsu M (1997) The NCEP regional spectral model: an update. Bull Am Meteorol Soc 78:2125-2143

Kistler R, Kalnay E, Collins W, Saha S, White G, Woollen J, Chelliah M, Ebisuzaki W, Kanamitsu M, Kousky V, van den Dool H, Jenne R, Fiorino M (2001) The NCEP-NCAR 50-year reanalysis. Bull Am Meteorol Soc 82:247-267

Klaassen J (2003) An analysis of heating degree days at selected Ontario locations. A report prepared for Enbridge Consumers Gas. Meteorological Service of Canada-Ontario Region, Environment Canada, Toronto, Ontario, Canada

Kunkel KE, Liang XZ, Zhu J (2010) Regional climate model projections and uncertainties of US summer heat waves. J Clim 23(16):4447-4458

Kyselý J, Plavcová E, Davídkovová H, Kynčl J (2012) Comparison of hot and cold spell effects on cardiovascular mortality in individual population groups in the Czech Republic. Clim Res 49(2):113-129

Lemmen DS, Warren FJ, Lacroix J, Bush E (eds) (2008) From impacts to adaptation: Canada in a changing climate 2007. Government of Canada, Ottawa, p 448

Ma T, Wu Z, Jiang Z (2012) How does coldwave frequency in China respond to a warming climate? Clim Dyn 39:2487-2496

Mailhot A, Beauregard I, Talbot G, Caya D, Biner S (2011) Future changes in intense precipitation over Canada assessed from multi-model NARCCAP ensemble simulations. Int J Climatol 32(8):1151-1163

Mearns LO, Arritt R, Biner S, Bukovsky MS, McGinnis S, Sain S, Caya D, Correia J Jr, Flory D, Gutowski W, Takle ES, Jones R,
Leung R, Moufouma-Okia W, McDaniel L, Nunes AMB, Qian Y, Roads J, Sloan L, Snyder M (2012) The North American regional climate change assessment program: overview of phase I results. Bull Am Meteorol Soc 93(9):1337-1362

Millerd F (2005) The economic impact of climate change on Canadian commercial navigation on the Great Lake. Can Water Resour J 30(4):269-280

Mladjic B, Sushama L, Khaliq MN, Laprise R, Caya D, Roy R (2011) Canadian RCM projected changes to extreme precipitation characteristics over Canada. J Clim 24(10):2565-2584

Nickels S, Furgal C, Buell M, Moquin H (2006) Unikkaaqatigiit-putting the human face on climate change: perspectives from Inuit in Canada. Joint Publication of Inuit Tapiriit Kanatami, Nasivvik Centre for Inuit Health and Changing Environments at Université Laval and the Ajunnginiq Centreat the National Aboriginal Health Organization, Ottawa

Pal JS et al (2007) Regional climate modeling for the developing world: the ICTP RegCM3 and RegCNET. Bull Am Meteorol Soc 88:1395-1409

Parkinson AJ, Butler JC (2005) Potential impacts of climate change on infectious diseases in the Arctic. Int $\mathrm{J}$ Circumpolar Health 64(5):478-486

Peings Y, Cattiaux J, Douville H (2013) Evaluation and response of winter cold spells over Western Europe in CMIP5 models. Clim Dyn 41(11-12):3025-3037

Plummer DA et al (2006) Climate and climate change over North America as simulated by the Canadian RCM. J Clim 19(13):3112-3132

Pope VD et al (2000) The impact of new physical parameterizations in the Hadley Centre climate model: HadAM3. Clim Dyn $16: 123-146$

Prowse T et al (2011) Past and future changes in Arctic lake and river ice. Ambio 40(1):53-62

Ramos AM, Trigo RM, Santo FE (2011) Evolution of extreme temperatures over Portugal: recent changes and future scenarios. Clim Res 48(2):177-192

Shabbar A, Bonsal B (2003) An assessment of changes in winter cold and warm spells over Canada. Nat Hazards 29(2):173-188

Sillmann J, Kharin VV, Zwiers FW, Zhang X, Bronaugh D (2013) Climate extremes indices in the CMIP5 multimodel ensemble: part 2. Future climate projections. J Geophys Res Atmos 118:2473-2493

Vautard R, Gobiet A, Jacob D, Belda M, Colette A, Déqué M, Fernández J, García-Díez M, Goergen K, Güttler I, Halenka T, Karacostas T, Katragkou E, Keuler K, Kotlarski S, Mayer S, van Meijgaard E, Nikulin G, Patarčić M, Scinocca J, Sobolowski S, Suklitsch M, Teichmann C, Warrach-Sagi K, Wulfmeyer V, Yiou $P$ (2013) The simulation of European heat waves from an ensemble of regional climate models within the EURO-CORDEX project. Clim Dyn 41(9-10):2555-2575

Vincent LA, Mekis E (2006) Changes in daily and extreme temperature and precipitation indices for Canada over the twentieth century. Atmos Ocean 44(2):177-193

Wang W, Shao Q, Yang T, Peng S, Yu Z, Taylor J, Xing W, Cuiping $\mathrm{Z}$, Sun $\mathrm{F}$ (2013) Changes in daily temperature and precipitation extremes in the Yellow River Basin, China. Stoch Env Res Risk Assess 27(2):401-421

Wehner M (2013) Very extreme seasonal precipitation in the NARCCAP ensemble: model performance and projections. Clim Dyn 40:59-80

Zhang X, Alexander L, Hegerl GC, Jones P, Tank AK, Peterson TC, Trewin B, Zwiers FW (2011) Indices for monitoring changes in extremes based on daily temperature and precipitation data. WIREs Clim Change 2:851-870 